\title{
UN NOU SIGNACULUM DIN DACIA ROMANĂ
}

\section{REZUMAT:}

Signaculum-ul de fier descoperit în cercetările arheologice preventive (2021) din vicus-ul roman de la Sutor (jud Sălaj), conține următoarea ștampilă: $N$ (umeri) $M$ (aurorum) [O(ptatianensium)]. În Dacia au fost descoperite nouă signacula fereea. Cronologic, piesa în discuție poate fi datată în intervalul cuprins între a doua jum. a sec. II-primele decenii ale sec. III d.Chr.

\section{AbSTRACT: A NeW SignaCUlum FROM Roman DaCIA}

The iron signaculum discovered in the preventive archeological excavations (2021) at the Roman vicus from Sutor (Sălaj County), contains the following stamp: $N$ (shoulders) $M$ (aurorum) [O (ptatianensium)]. In Dacia only nine signacula fereea were discovered so far. Chronologically, the object in question can be dated in the interval between the second half of the 2nd century AD and the first decades of the 3rd century AD.

CUVINTE CHEIE: Dacia romană, Sutor, vicus militar, signacula ferrea, numerus Maurorum Optatianensium.

KEYWORDS: Roman Dacia, Sutor, military vicus, signacula ferrea, numerus Maurorum Optatianensium.

În ultimii treizeci de ani epigrafiștii au acordat o atenție mai mare epigrafiei minora cuprinsă sub termenul de instrumenta inscripta Latina. Sub acest termen sunt definite artefacte ce poartă înscrisuri: cuvinte, litere, nume proprii, ștampile de producători (officina), rețete medicale, nume de unități militare, graffiti, etc. Acest instrumentum poate releva documente importante pentru istoria militară și viața economică, cotidianul artizanal al lumii romane. Cercetările mai recente au condus și la organizarea unor colocvii internaționale finalizate în cele mai multe cazuri prin volume colective ${ }^{1}$. La nivelul Daciei cele mai importante contribuții privitoare la instrumentum domesticum aparțin lui D. Isac ${ }^{2}$ și C. L. Băluțăa

În categoria instrumentum domesticum, signacula sunt printre din cele mai bine documentate grupe de artefacte. Materialul de execuție al acestor piese este variat: fier, bronz, plumb, piatră, ceramică, lemn.

Signacula ferrea au fost analizate mai intens după mijlocul secolului trecut ${ }^{4}$. În ultimele două decenii au fost publicate puține piese noi ${ }^{5}$. De remarcat este studiul cercetătoarei G. Baratta care oferă o primă sinteză despre signacula de fier ${ }^{6}$. Lucrarea analizează modul de utilizare al fiecărei piese, respectiv la cald și prin presare? ${ }^{7}$. În cea ce privește funcționalitatea lor, autoarea se pronunță pentru folosirea lor în marcarea animalelor, a produselor de piele și lemn, dar nu exclude și folosirea lor pentru aplicarea pe corpul uman ${ }^{8}$.

Repertoriul cuprinde un corpus al descoperirilor din Imperiul roman (50 de piese printre care și două piese de

IIL I, IIL II, IIL III, IIL V, IIL VI, IIL VIII.

Isac $1991=$ Isac 2001, 70-79.

IDR III/6.

4 Klumbach 1952, 1-12; Gherasimov 1959, 339-342; Spitzelberger 1968, 110; Garbsch 1970, 110-112; Gaitzsch 1980, 270; Burger 1987, 116, fig. 102; Visy 1977, 9; Isac 1991; Desbat 1991, 323-325.

5 Pietsch 2000, 297-301; Baratta 2004, 189-190; Baratta 2007, 99-108; Krier 2007, 18-22; Mezquíriz Irujo 2007-2008, 212, nr. 26; Pfahl 2012, 200, pl. 80, 518; Ronke 2015, 371-387; Teichner și Dürr 2021, 887, cat. nr.8-11.

6 Baratta 2007, 99-108.

7 Baratta 2007, 99.

8 Baratta 2007, 100-103. 
bronz). Un apendice cu ultimele descoperiri completează repertoriul inițial. Din păcate Dacia este cvasiocolită

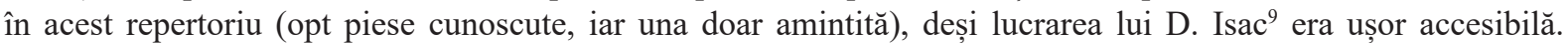
Tot referitor la Dacia probabil că signaculum-ul de bronz din Colonia Ulpia Traiana Sarmizegetusa amintită în apendice "BBB" este identică cu cea publicată de D. Isac (TIB C C) ${ }^{10}$. Din acest repertoriu mai lipsesc şi piesele din Panonnia ${ }^{11}$.

Signacula ex aere au fost cercetate intens în ultimele decenii cu precădere în provinciile vestice ${ }^{12}$.

$\mathrm{Cu}$ ocazia cercetărilor arheologice preventive din vicus-ul adiacent castrului roman de la Sutor au fost investigate zonele peste care se va construi o parte a subsecțiunii 3B1: Mihăiești-Zimbor (km 12+580 - km 13+260) a autostrăzii Cluj-Oradea. Suprafața S2 $(145 \times 65$ m), cercetată parțial, a relevat o structură de lemn de mari dimensiuni, probabil o magazie sau un antrepozit, o a doua structură de lemn, o bucată din artera de drum roman care leagă drumul imperial de Bologa precum și o zonă cu caracter meșteșugăresc situată în partea de nord a suprafeței din care a putut fi cercetat un atelier ceramic ${ }^{13}$. Între a doua structură de lemn și drumul roman a fost identificat în dărâmătura ultimului nivel de locuire roman signaculum-ul din fier ${ }^{14}$.

Piesa este fragmentară, fiind executată prin forjare dintr-o singură bucată de metal. Dimensiunile sunt după cum urmează: înălţimea păstrată = 24,3 cm; lățimea păstrată $=3,9 \mathrm{~cm}$; lungimea brațelor $=6,5 \mathrm{~cm}$; grosimea tijei $=1,6$ $\mathrm{cm}$, grosimea literelor $=0,78 \mathrm{~cm}$, înălțimea literelor $=3,1-3,4 \mathrm{~cm}$.

Din trunchiul principal pornesc trei brațe. Deși unul din brațe lipsește, pe baza examinării primare, a fotografierii înaintea restaurării piesei și a fotografiei Röntgen putem suține existența a trei brațe (pl. II/4-5). Pe fiecare braț se afla câte o literă. Prima literă de pe brațul lateral este păstrată fragmentar (pl. II/1-2; pl. IV/3-4). Litera păstrată la o primă vedere ar putaea fi I, dar se păstrează în partea de jos un început de îndoire spre dreapta cea ce poate indica litera N sau M. Cea de a doua literă aflată pe axul principal la o primă constatare pare a fi litera N, dar în partea de sus din dreapta avem o mică îndoitură care ar sugera mai mult litera M (pl. II/1-2; pl. IV/3-4). Propunem pentru brațul lipsă litera O. Lectura completă care o propunem este N(umeri) M(aurorum) [O(ptatianensium)]. Această unitate militară este cunoscută în castrul de Sutor prin peste 30 de ștampile militare ${ }^{15}$. Signacula cu numele unor unității militare sunt cunoscute atât în Dacia ${ }^{16}$ cât și în Imperiu ${ }^{17}$. Piesa mai sus analizată face parte din tipul 1 din tipologia lui D. Isac ${ }^{18}$. Conform lui D. Isac signacula de fier sunt folosite pentru marcarea animalelor, dar fără a exclude pe baza bibliografiei prezentate folosirea lor și pentru ștampilare pe piele, lemn sau cărămizi ${ }^{19}$.

Referitor la tipologia lui D. Isac pentru signacula din Dacia ea poate fi extinsă pe baza tipologiei europene și a unor descoperi mai vechi sau noi din Dacia, cu tipul III pentru signacula din plumb ${ }^{20}$, tipul IV signacula din ceramică ilustrat în Dacia prin exemplarul de la Napoca ${ }^{21}$, tipul V signacula oculariorum. Acestea din urmă sunt ștampile confecționate din piatră de formă paralelipipedică având de obicei inscripții pe toate laturile. Din Dacia cunoaștem două exemplare, descoperite la Apulum ${ }^{22}$ și în villa de la Gârbou ( județul Sălaj) ${ }^{23}$.

Revenind la signacula ferrea din Dacia trebuie să remarcăm numărul mare al acestora. Astfel, sunt cunoscute nouă piese provenind din șase situri, mai ales militare, dar și civile. Raportat la numărul pieselor cunoscute la nivelul Imperiului roman (65 exemplare), numărul pieselor descoperite în provincie este mare dovedindu-se și prin aceste artefacte înscrierea deplină a Daciei în civilizația romană.

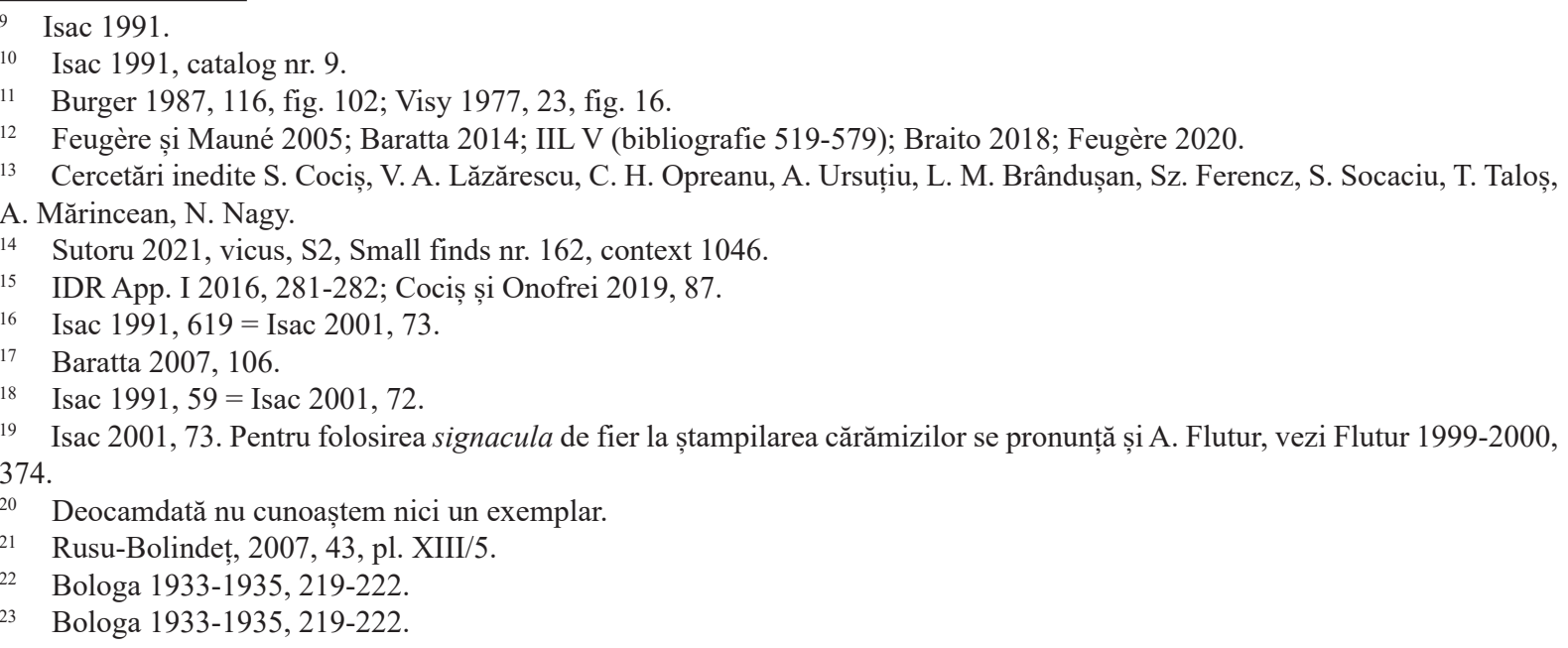




\section{ABREVIERI}

IDR III/6

Inscripțiile Daciei romane (Inscripțiile antice din Dacia și Scythia Minor, Seria primă), Vol. III: Dacia Superior 6. Apulum - Instrumentum Domesticum (adunate, însoţite de comentarii şi indice, traduse de C. L. Băluță), București, 1999.

IDR App. I 2016

Piso, I. și Deac, D. 2016. Inscriptiones Daciae Romanae. Appendix I Inscriptiones laterum Musei Zilahensis, Cluj-Napoca 2016.

IIL I

Instrumenta inscripta Latina-Gesellschaftliche und wirtschaftliche Probleme des Romischen Reiches im Spiegel der Gelegenheits und reproduzierte Inschriften, în Specimina Nova VII/1, 1991 (1992).

IIL II

Instrumenta inscripta latina II. Akten des 2. internationalen Kolloquiums, Klagenfurt, 5.-8. Mai 2005, Volumul 2, ed. M. Hainzmann, R. Wedenig (ed.), Klagenfurt, 2008.

IIL III

Instrumenta inscripta III. Manufatti iscritti e vita dei santuari in età romana, G. Baratta, S. M. Marengo (ed.), Macerata, Edizioni Università di Macerata, 2012.

IIL V

Instrumenta Inscripta V. Signacula ex aere: aspetti epigrafici, archeologici, giuridici, prosopografici, collezionistici, A. Buonopane, S. Braito (ed.). Atti del convegno internazionale (Verona, 20-21 settembre 2012), Roma, 2014.

IIL VI

Instrumenta inscripta VI. Le iscrizioni con funzione didascalicoesplicativa, M. Buora, S. Magnani (ed.), Atti del VI Incontro Instrumenta Inscripta (Aquileia, 26-28 marzo 2015), în Antichità Altoadriatiche 83, 2016.

IIL VIII Instrumenta inscripta VIII, Plumbum litteratum: Studia epigrafica Giovanni Mennella oblate, G. Baratta (ed.), Scienze e lettere, Roma, 2021.

\section{BIBLIOGRAFIE}

Baratta, G. 2004. Nota su un ferro per marcare (signaculum) del Museo Archeologico di Spalato, in Ciongradi, C., Ardevan, R., Roman, C., Găzdac, C. (eds), Orbis Antiquus. Studia in Honorem Ioannis Pisonis: 189-190. Cluj-Napoca: Editura Nereamia Napocae.

Baratta, G. 2007. Una particolare categoria di signacula: Marchi per legno, pellame ed animali, în Acta XII Congressus Internationalis Epigraphiae Graecae et Latinae Barcelona 2002 = MonogrSecció Hist.-Arqueológica 10: 99-108. Barcelona: Institut d'Estudis Catalans.

Baratta, S. 2014. Tre signacula bronzei dalle Isole Baleari (Menorca e Mallorca). Sylloge Epigraphica Barcinonensis XII: $181-192$.

Rusu-Bolindeț, V. 2007. Ceramica romană de la Napoca. Contribuţii la studiul ceramicii din Dacia romană. Bibliotheca Musei Napocensis XXV. Cluj-Napoca: Editura Mega.

Bologa, V.L. 1933-1935. Interpretarea medicală a celor două ștampile de oculiști din Dacia Superioară. Anuarul Institutului de Studii Clasice: 219-222.

Braito S. 2018. Nuovi signacula ex aere dal mercato antiquario online (parte 3). Sylloge Epigraphica Barcinonensis XVI: 265-279.

Burger, A. Sz. 1987. The Roman Villa and Mausoleum at Kővágószőlős, near Pécs (Sopianae), Excavations 19771982. Janus Pannonius Múzeum Évkönyve 30-31: 65-229.

Cociş S. şi Onofrei C. 2019. Cohors I Brittonum on a tile stamp found at Sutoru, în Farkas, I. G., Neményi, R., Szabó, M. (edd.), Artificem commendat opus. Studia in honorem Zsolt Visy: 29-36. Pécs: CLIR Research Center.

Desbat, A. 1991. Un buchón de bois du 1er s. aprés J.-C. recueilli dans la Saóne á Lyon et la question du tonneau á l'époque romaine. Gallia 48: 319-333.

Feugère, M. și Mauné, S. 2005. Les signacula de bronze en Gaule Narbonnaise. Revue archéologique de Narbonnaise 38-39: 437-455.

Feugère, M. 2020. Signacula ex aere : épigraphie et matérialité. Le Fil d'ArAr 19/08/2020: https://lefildarar. hypotheses.org/3811. 
Flutur, A. 1999-2000. Despre două ştampile tegulare de la Tibiscum. Analele Banatului, arheologie istorie VIIVIII: 373-376.

Gaitzsch, W. 1980. Eiserne Romische Werkzeuge: Studien zur roemischen Werkzeugkunde in Italien und den noerdlichen Provinzen des Imperium Romanum. British Archaeological Reports International Series 78. Oxford: BAR Publishing.

Garbsch, J. 1970. Eisenfunde aus Eining. Bayerische Vorgeschiteblatter 35: 105-112.

Gherasimov, T. 1959. Anciens outils de fer á marquer. Bulletin de L'Institut Archéologique Bulgare XXII: 339-342. Isac, D. 1991. Signacula aus Dakien. Saalburg-Jahrbuch 46: 57-64.

Isac, D. 2001. Viaţă cotidiană în castrele Daciei Porolissensis. Cluj-Napoca: Editura Napoca Star.

Klumbach, H. 1953. Pferde mit Brandmarken. Festschr. RGZM zur Feier seines hundertjährigen Bestehens 1952, Bd. 3: 1-12.

Krier, J. 2007. Ein Eisenhortfund der frühen Kaiserzeit aus Goeblingen-,Miecher'. Den Ausgriewer - D'Zeitung vun D'Georges Kayser Altertumsfuerscher 17: 18-22.

Mezquíriz Irujo, M. A. 2007-2008. Instrumentos de hierro para la explotación agropecuaria en época romana. Trabajos de arqueología Navarra 20: 197-208.

Pfahl, St. F. 2012. Instrumenta latinae et graecae inscriptae des Limesgebietes von 200 v.Chr. bis 600 n.Chr. Weinstadt: Greiner, Bernhard A.

Pietsch, M. 2000. Ein römischer Viehbrennstempel aus Straubing. Jahresbericht des Historischen Vereins für Straubing und Umgebung, 1998 (2000): 297-301.

Renard, M. 1961. Note épigraphique sur le tonneau romain de Harelbeke. Latomus XX: 785-799.

Ronke, J. 2015. Frühes 'Branding the cattle' - Brandmarken für Pferde. Fundberichte aus Baden-Württemberg 35: 371-387.

Spitzelberger, G. 1968. Die rómischen Zielegstempel im nordlichen Teil der Provinz Raetien. Saalburg Jahrbuch 25: 65-184.

Taglietti, F. 1994. Un inedito bollo laterizio ostiense ed il commercio dell'olio betico, în Actes de la VIIe Rencontre franco-italienne sur l'épigraphie du monde romain (Rome, 5-6 juin 1992): 157-193. Roma: Publications de l'École Française de Rome.

Teichner, F. și Dürr, R. 2021. Eine römische Eisenwarenhandlung in der dardanischen Bergbaustadt Ulpiana (Moesia Superior), în Leger, E C. și Raux, S. (ed.), Des objets et des hommes. Etudes offertes à Michel Feugère. Paris: Editons Mergoil.

Visy, Z. 1977. Intercisa. A római kori Dunaújváros. Budapest: Corvina Kiadó. 


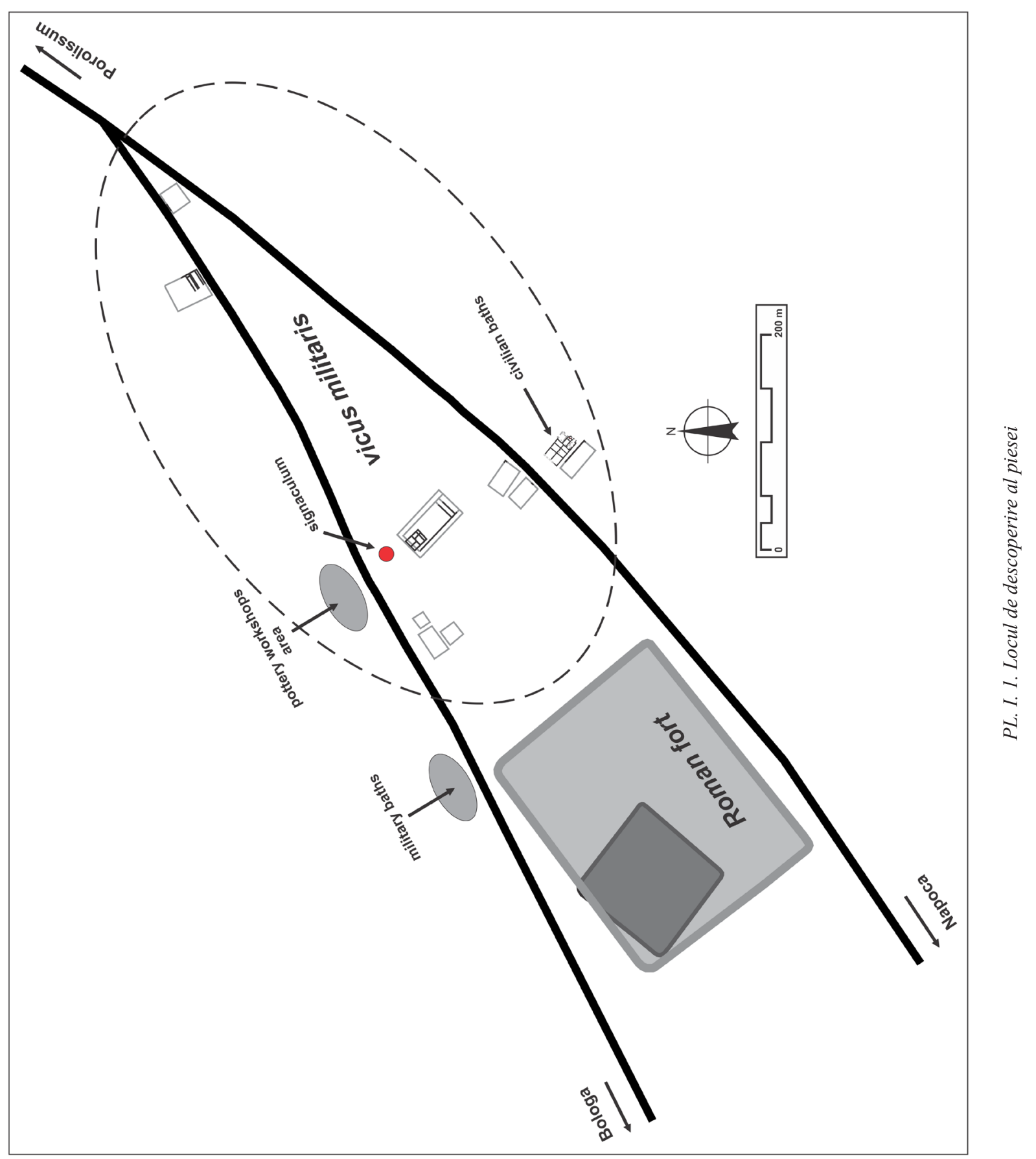


1.

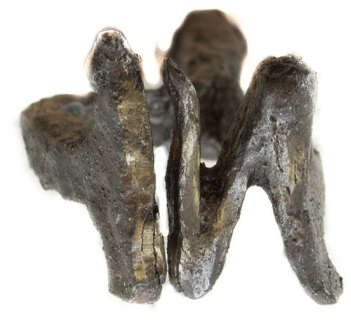

2.

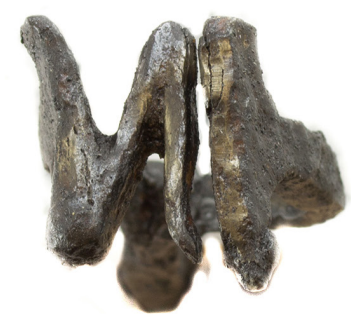

||||||||||||||||||||||||||||||||||||||

$\begin{array}{llll}0 & 1 & 2\end{array}$

$\mathrm{cm}$

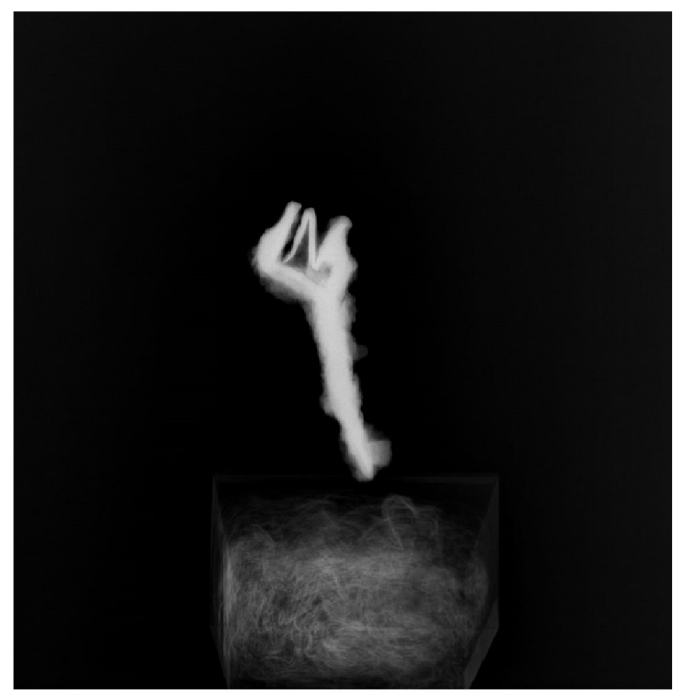

3.

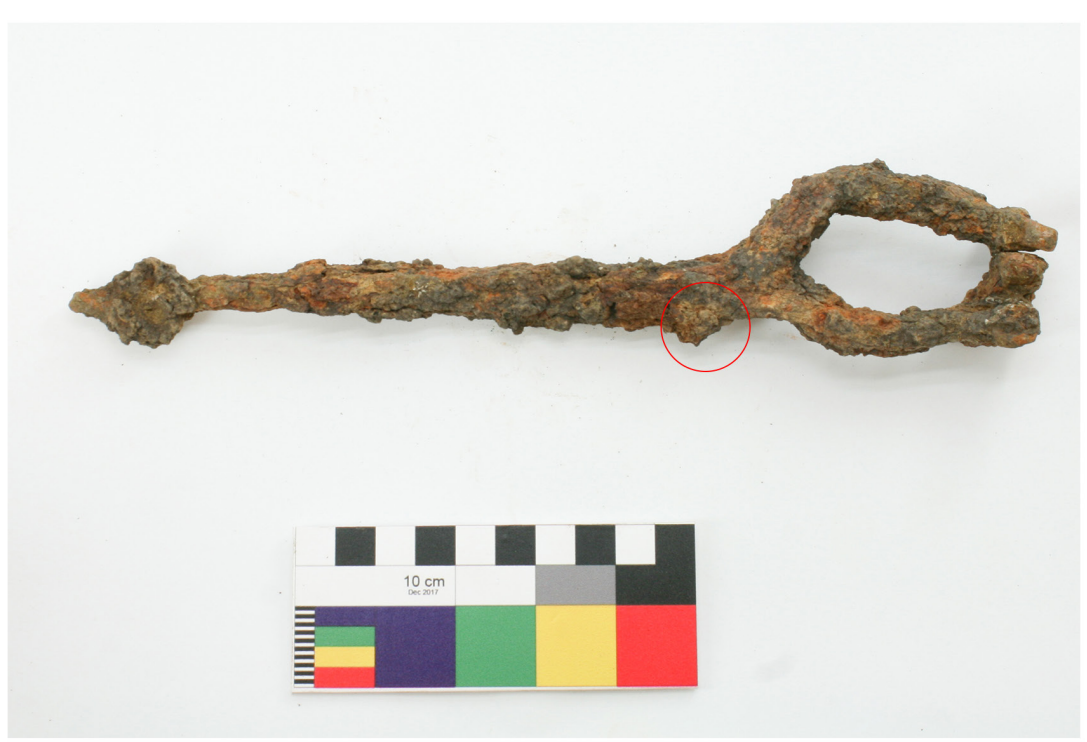

4.

5.

PL. II. 1. Signaculum de la Sutor, foto cu inscripția; 3-4 Foto-Röntgen; 5. Foto inainte de restaurare. 


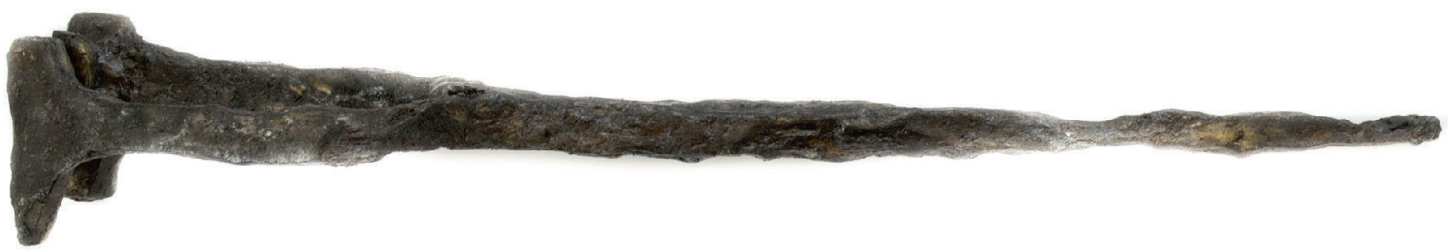

1.

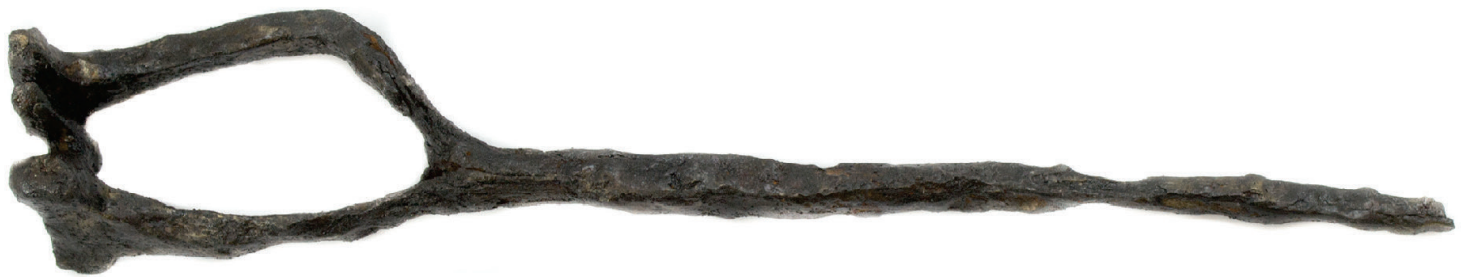

2.

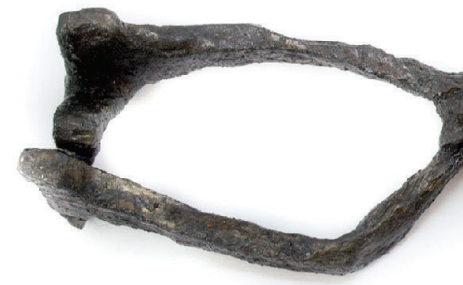

3.

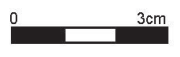

PL. III. 1-3. Signaculum de la Sutor foto după restaurare. 

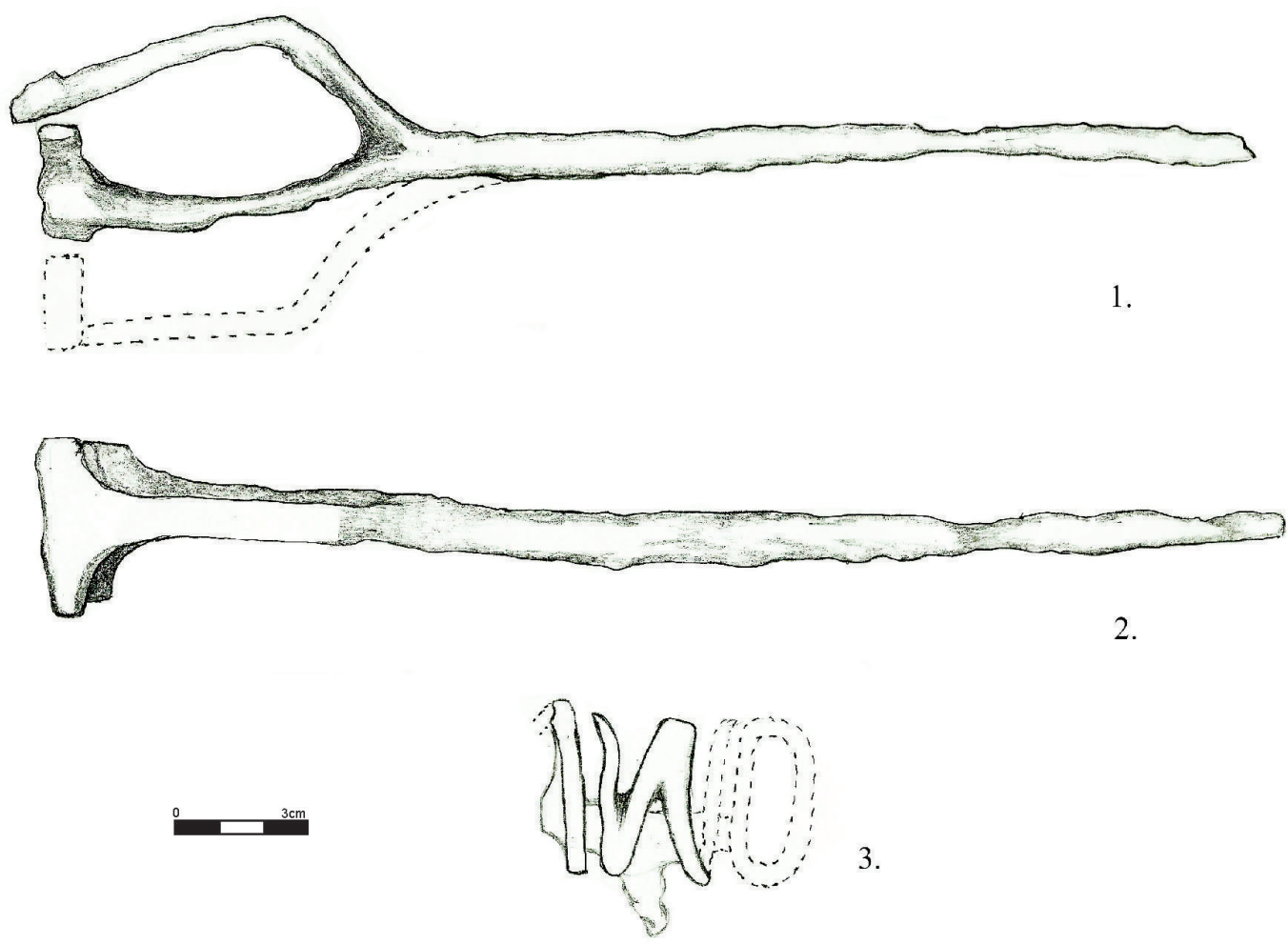

3.

PL. IV.1-3. Signaculum de la Sutor, desen.

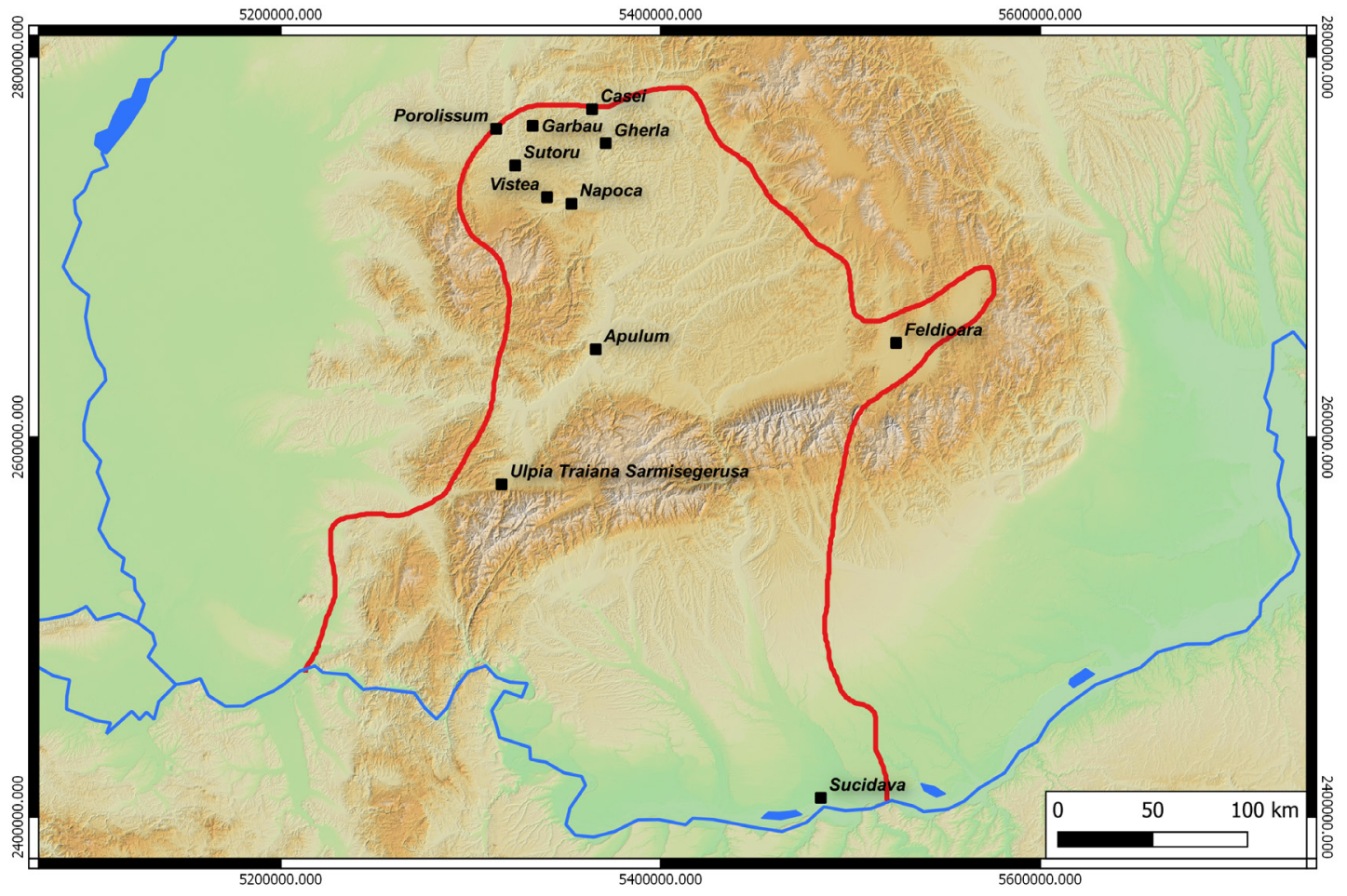

PL.V. Lista localităților cu descoperiri de signacula din Dacia. 